\title{
PENGEMBANGAN PERANGKAT PEMBELAJARAN MODEL INKUIRI TERBIMBING BERBANTUAN MEDIA AUDIOVISUAL UNTUK MENINGKATKAN PENGUASAAN KONSEP ALAT-ALAT OPTIK
}

\author{
(bnu Saputra ${ }^{1)}$, Verawati ${ }^{11}$, Hikmawati ${ }^{1)}$ \\ Program Studi Pendidikan Fisika FKIP, Universitas Mataram, NTB, Indonesia \\ Corresponding author : Ibnu Saputra \\ E-mail : ibnum395@gmail.com
}

\section{Diterima 04 Januari 2021, Direvisi 08 Maret 2021, Disetujui 14 Maret 2021}

\begin{abstract}
ABSTRAK
Penelitian ini bertujuan mendeskripsikan validitas dan reliabilitas perangkat pembelajaran model inkuiri terbimbing berbantuan media audiovisual untuk meningkatkan penguasaan konsep optika geometri. Jenis penelitian digunakan yaitu penelitian pengembangan (Research and Development) dengan rancangan penelitian pengembangan modifikasi model Borg dan Gall. Subjek penelitian ini yaitu perangkat pembelajaran berbasis model inkuiri terbimbing berbantuan media audiovisual. Pengambilan data penelitian menggunakanlembar validasi yang dinilai oleh 4 validator ahli, terdiri dari 2 dosen pendidikan fisika dan 2 guru mata pelajaran fisika. Data penelitian berupa data kualitatif dan kuantitatif dari penilaian validator terhadap perangkat pembelajaran yang dikembangkan. Perangkat pembelajaran tersebut meliputi silabus, RPP, LKPD, video pembelajaran dan tes penguasaan konsep. Penelitian ini melakukan uji validitas dan reliabilitas untuk menentukan kelayakandari perangkat pembelajaran. Data hasil validitas diperoleh nilai 3,33(silabus), 2,98 (RPP), 3,07 (LKPD), 3,08 (video pembelajaran) dan 3,00 (penguasaan konsep), sehingga rata-rata validitas perangkat pembelajaran berada pada kategori valid dengan tingkat validitas yaitu 3,09 , selanjutnya yaitu uji reliabilitas, diperoleh hasil interval koefisien yaitu 0,886 (silabus), 0,808 (RPP), 0,829 (LKPD), 0,894 (video pembelajaran ) dan 0,702 (tes penguasaan konsep), sehingga rata-rata interval koefisien reliabilitas yaitu 0,823 dengan kategori sangat tinggi. Kesimpulannya bahwa perangkat pembelajaran telah layak dalam arti valid dan reliable untuk digunakan dalam kegiatan pembelajaran.
\end{abstract}

Kata kunci : pengembangan perangkat pembelajaran; model inkuiri terbimbing; penguasaan konsep.

\begin{abstract}
This study aims describe the validity and reliability of the instructional guided inquiry model assisted by audiovisual media used in learning. The type research used is research development (Research and Development) with a modified development research design of the Borg and Gall model. The subject of this research is the XI IPA learning device at SMA Negeri 1 Gerung. Retrieval of research data through a validation questionnaire assessed by 4 validators, namely 2 physics lecturers and 2 physics teachers. The research data is in the form of qualitative and quantitative data from the validator's assessment of the learning tools developed. The learning tools include syllabus, lesson plans, student worksheet, video lessons and concept mastery tests. This study conducted a validity test to determine the characteristics and level of validity of the learning device. The validity data obtained were 3.33 (syllabus), 2.98 (RPP), 3.07 (LKPD), 3.08 (instructional videos) and 3.00 (concept mastery test). So that the average characteristics of learning devices are in the valid category with a validity level of 3.09 , furthermore, the reliability test, the coefficient interval results obtained are 0.886 (syllabus), 0.808 (lesson plans), 0.829 (student worksheet), 0.894 (learning videos) and 0.702 (concept mastery tests). So that the average reliability coefficient interval is 0.823 with a very high category. The conclusion is that the learning device is feasible and reliable for use in learning.
\end{abstract}

Keywords: development of learning tools; guided inquiry; mastery of concepts.

\section{PENDAHULUAN}

Pendidikan merupakan upaya membangun peradaban, sebagai suatu bentuk kegiatan kehidupan dalam masyarakat untuk mewujudkan manusia seutuhnya yang berlangsung sepanjang hayat. Mencerdaskan kehidupan bangsa dan mengembangkan kualitas manusia seutuhnya adalah misi pendidikan yang menjadi tanggung jawab profesional setiap guru (Mulyasa, 2013). Pada kondisi yang diharapkan, proses pembelajaran fisika seharusnya mampu membuat peserta 
didik secata aktif dengan dominasi kegiatan penyelidikan, kemudian mengumpulkan data dan menganalisis data sehingga peserta didik memiliki kemampuan untuk menemukan konsep materi dengan tepat.

\section{METODE PENELITIAN}

Jenis Penelitian ini adalah penelitian pengembangan (Research and Development). Pengembangan perangkat pembelajaran mengacu pada rancangan penelitian dan pengembangan modifikasi model Borg dan Gall (Sugiyono, 2014).

Instrumen penelitian berupa perangkat pembelajaran dan angket penilaian validator. Kemudian metode penelitian yaitu meliputi 5 tahap yaitu, penelitian dan pengumpulan data, perencanaan produk, pengembangan produk awal, uji kelayakan dan revisi produk final. Sedangkan teknik pengambilan data yaitu melalu angket penilaian yang dinilai oleh 4 validator, terdiri atas 2 dosen ahli/fisika, dan 2 guru mata pelajaran fisika. Sehingga diperoleh data kualitatif yaitu berupa saran dan masukan validator dan data kuantitatif yaitu skor penilaian validator.

Perangkat pembelajaran yang dikembangkan terdiri dari Silabus, Rencana Pelaksanaan Pembelajaran (RPP), Lembar Kegiatan Peserta Didik (LKPD), dan Video Pembelajaran serta instrumen soal evaluasi penguasaan konsep. Hasil validasi berupa skor angket validasi untuk mencari nilai validitas dan reliabilitas produk dengan rumus:

$\bar{V}=\frac{\sum_{j=1}^{n} \overline{A_{l j}}}{n}$ dan $P A=\left[1-\frac{A-B}{A+B}\right] 100 \%$

Dimana, $\bar{V}$ : validitas, $A_{i j}$ : rata-rata nilai aspek, $\mathrm{n}$ : banyak aspek, $P A$ : reliabilitas instrumen (percentage of agreetment), A : nilai tertinggi validator untuk suatu aspek, $B$ : nilai terendah validator untuk suatu aspek (Trianto, 2010).

\section{HASIL DAN PEMBAHASAN}

Penelitian ini dimulai dengan tahap observasi yaitu sebagai tahap penelitian dan pengumpulan data. Observasi dilakukan di SMAN 1 Gerung dengan melalui angket pertanyaan untuk peserta didik dan untuk guru serta mengamati langsung proses pembelajaran di kelas. Tujuannya yaitu menemukan kesenjangan antara kondisi yang diharapkan dengan kenyataan yang terjadi dalam proses pembelajaran. Diperoleh kesenjangan berupa anggapan fisika sebagai pelajaran sulit dan membosankan dari peserta didik, lemahnya penguasaan konsep peserta didik serta kurang bervariasinya media pembelajaran yang digunakan guru.
Tahap selanjutnya yaitu perencanaan produk yang merupakan penggambaran terkait solusi untuk mengatasi masalah yang ditemukan. Selanjutnya dari penggambaran tersebut disimpulkan untuk mengembangkan perangkat pembelajaran model inkuiri terbimbing berbantuan media audiovisual. Tindak lanjut dari solusi tersebut yaitu tahap pengembangan produk, dengan maksud untuk menghasilkan produk perangkat pembelajaran yang dimaksudkan mampu menjadi solusi terhadap masalah tersebut. Produk perangkat pembelajaran terdiri atas silabus, RPP, LKPD, video pembelajaran dan tes penguasaan konsep.

Setelah melalui tahap pengembangan, produk perangkat pembelajaran akan melalui tahap uji kelayakan. Tujuannya yaitu untuk melihat efisien, efektivitas maupun ketepatan dan kebenaran produk. Uji kelayakan disini peneliti menggunakan penilaian validator ahli, sehingga produk tidak melalui tahap uji coba. $\mathrm{Hal}$ ini atas pertimbangan kondisi saat penelitian yaitu situasi pandemi covid-19 serta keterbatasan waktu peneliti dalam menyelesaikan penelitian. Sehingga fokus utama untuk mencapai tujuan penelitian yaitu mencapai produk perangkat pembelajaran yang valid dan layak terdapat pada tahap uji kelayakan ini.

Adapun hasil dari tahap uji kelalayakn tersebut berupa data kuantitatif yaitu skor penilaian angket validasi perangkat pembelajaran. Data tersebut kemudian digunakan dalam menguji validitas dan reliabilitas perangkat pembelajaran. Hasil analisisnya yaitu sebagai berikut.

Tabel 2.Total Penilaian Validator Terhadap Setiap Perangkat Pembelajaran

\begin{tabular}{|c|c|c|c|c|c|}
\hline \multirow[t]{2}{*}{ No } & \multirow{2}{*}{$\begin{array}{c}\text { Perangkat } \\
\text { Pembelajaran }\end{array}$} & \multicolumn{4}{|c|}{$\begin{array}{c}\text { Total Skor Penilaian } \\
\text { Validator }\end{array}$} \\
\hline & & I & II & III & IV \\
\hline 1 & Silabus & 2,91 & 3,5 & 3,25 & 3,66 \\
\hline 2 & RPP & 13,99 & 19,58 & 17,57 & 20,66 \\
\hline 3 & LKPD & 9,83 & 13,82 & 11,58 & 13,91 \\
\hline 4 & $\begin{array}{l}\text { Video } \\
\text { Pembelajaran } \\
\text { Tes }\end{array}$ & 2,76 & 2,94 & 3,21 & 3.42 \\
\hline 5 & $\begin{array}{l}\text { Penguasaan } \\
\text { Konsep }\end{array}$ & 7,83 & 13,16 & 12,66 & 14,5 \\
\hline $\begin{array}{l}\text { ba } \\
\text { pe } \\
\text { ke } \\
\text { rat } \\
\text { set } \\
\text { dib } \\
\text { rel } \\
\text { de } \\
\text { ter }\end{array}$ & $\begin{array}{l}\text { Berdasarka } \\
\text { wa terdapat sel } \\
\text { ilaian setiap per } \\
\text { mpat validator. } \\
\text {-rata dari bany } \\
\text { ap perangkat } \\
\text { ituhkan untuk } \\
\text { abiltas setiap per } \\
\text { gan menggunak } \\
\text { ndah. }\end{array}$ & $\begin{array}{l}\text { tabel } \\
\text { sih/perb } \\
\text { angkat } \\
\text { Skor te } \\
\text { aknya } \\
\text { pembe } \\
\text { nemper } \\
\text { angkat } \\
\text { an skor }\end{array}$ & $\begin{array}{l}\text { di at } \\
\text { daaan } \\
\text { embel } \\
\text { sebut } \\
\text { idikato } \\
\text { ajaran. } \\
\text { oleh n } \\
\text { embela } \\
\text { tertings }\end{array}$ & $\begin{array}{l}\text { s terli } \\
\text { skor ak } \\
\text { aran o } \\
\text { erupak } \\
\text { penila } \\
\text { Nilai } \\
\text { ai ting } \\
\text { aran ya } \\
\text { dan s }\end{array}$ & \\
\hline
\end{tabular}


Tabel 3. Rekapitulasi Hasil Analisis Uji

Validitas Perangkat Pembelajaran

\begin{tabular}{clcc}
\hline No & $\begin{array}{l}\text { Perangkat } \\
\text { Pembelajaran }\end{array}$ & $\begin{array}{c}\text { Validitas } \\
(\bar{V})\end{array}$ & Kategori \\
\hline 1 & Silabus & 3,33 & Valid \\
\hline 2 & $\begin{array}{l}\text { Rencana } \\
\text { Pelaksanaan } \\
\text { Pembelajaran } \\
\text { (RPP) }\end{array}$ & 2,98 & Valid \\
\hline 3 & $\begin{array}{l}\text { Lembar } \\
\text { Kegiatan } \\
\text { Peserta Didik } \\
\text { (LKPD) }\end{array}$ & 3,07 & Valid \\
\hline 4 & $\begin{array}{l}\text { Video } \\
\text { Pembelajaran }\end{array}$ & 3,08 & Valid \\
\hline 5 & $\begin{array}{l}\text { Tes } \\
\text { Penguasaan } \\
\text { Konsep }\end{array}$ & 3,00 & Valid \\
\hline
\end{tabular}

Tabel di atas memaparkan tingkat validitas setiap perangkat pembelajaran, dimana rata-ratanya yaitu pada kategori valid dengan tingkat 3,09 . Dengan silabus memiliki tingkat validitas tertinggi $(3,33)$ dan RPP dengan tingkat validitas terrendah $(2,98)$. Hal ini dikarenakan silabus merupakan perangkat yang tidak terlalu banyak dimodifikasi dari bentuk umumnya serta cakupannya tidak luas. Sedangkan RPP merupakan perangkat yang cakupannya luas yaitu menyesuaikan dengan model pembelajaran inkuiri terbimbing, dengan kolaborasi media pembelajaran dalam proses pembelajaran, serta mencakup 3 rangkap karena untuk 3 pertemuan. Sehingga dalam menghasilkan produk RPP banyak yang harus dibenahi dan ditingkatkan lagi.

Hasil penelitian di atas selaras dan didukung oleh penelitian sebelumnya yaitu (Hermanto, dkk, 2016) dengan judul pengembangan perangkat pembelajaran IPA model inkuiri terbimbing untuk meningkatkan pemahaman konsep, diperoleh rata-rata tingkat validitas yaitu 3,70 dengan kategori sangat valid. Sehingga perangkat pembelajaran layak digunakan.

Tabel 4. Rekapitulasi Hasil Analisis Uji Reliabilitas Perangkat Pembelajaran

\begin{tabular}{lcc}
\hline $\begin{array}{c}\text { Perangkat } \\
\text { Pembelajaran }\end{array}$ & $\begin{array}{c}\text { Interval } \\
\text { Koefisien }\end{array}$ & Kategori \\
\hline Silabus & 0,886 & $\begin{array}{c}\text { Sangat } \\
\text { tinggi }\end{array}$ \\
\hline RPP & 0,808 & $\begin{array}{c}\text { Sangat } \\
\text { tinggi }\end{array}$ \\
\hline LKPD & 0,829 & $\begin{array}{c}\text { Sangat } \\
\text { tinggi }\end{array}$ \\
\hline $\begin{array}{l}\text { Video } \\
\text { Pembelajaran }\end{array}$ & 0,894 & $\begin{array}{c}\text { Sangat } \\
\text { tinggi }\end{array}$ \\
\hline $\begin{array}{l}\text { Tes } \\
\text { Penguasaan } \\
\text { Konsep }\end{array}$ & 0,702 & Tinggi \\
\hline
\end{tabular}

Sebelumnya adalah tabel tingkat validitas, selanjutnya tabel di atas merupakan tabel tingkat reliabilitas setiap produk perangkat pembelajaran. Berdasarkan tabel secara tidak langsung terlihat bahwa rata-rata reliabilitas perangkat pembelajaran yaitu pada kategori sangat tinggi $(82,3 \%)$. Dengan artian bahwa produk perangkat telah reliable ataupun layak digunakan.

Hasil di atas selaras dengan penelitian Budiarso (2017), diperoleh rata-rata tingkat reliabilitas dari perangkat pembelajaran yang meliputi RPP, BAS, LKPD dan tes hasil belajar yaitu $81,03 \%$ atau pada interval koefisien $(0,80$ $-1,00$ ) dengan kategori sangat tinggi dan siap digunakan dalam kegiatan pembelajaran dengan perlu sedikit perbaikan.

Pengkajian lebih lanjut berdasarkan tabel-tabel hasil analisis data di atas terdapat beberapa poin pembahasan. Pertama silabus dan RPP yang dihasilkan yaitu mengukuti format K-13, kemudian dalamnya memuat media pembelajaran yang bervariasi yaitu video pembelajaran dan LKPD. Kedua yaitu LKPD, menyesuaikan dengan sintak RPP inkuiri terbimbing sehingga pada fase ke 4 kegiatan inti LKPD digunakan. LKPD juga memuat identifikasi masalah dan pertanyaan yang akan dipercahkan oleh peserta didik dengan informasi pada video pembelajaran. Ketiga yaitu video pembelajaran yaitu memuat animasi sains dan informasi untuk keperluan peserta didik dalam menyelesaikan masalah/pertanyaan dalam LKPD, serta desain dan tampilannya sangat menarik. Selanjutnya yaitu tes penguasaan konsep yaitu berisi soal untuk mengukur tingkat penguasaan konsep peserta didik yang didalamnya mencakup pertanyaan dengan tingkat taksonomi Bloom mulai C1 sampai C6.

Terakhir yaitu berdasarkan rata-rata dari nilai validitas dan reliabilitas maka produk perangkat pembelajaran yang dihasilkan pada penelitian ini berada pada tingkat validitas $(3,09$ : valid) dan tingkat reliabilitas $(82,38 \%$ : sangat tinggi). Selaras dengan penelitian sebelumnya oleh Wahyuni, dkk (2018) telah melakukan pengembangan perangkat pembelajaran fisika berbasis inkuiri terbimbing untuk meningkatkan penguasaan konsep peserta didik. Menghasilkan rata-rata persentase kevalidan dari Silabus, RPP, LKPD, dan tes penguasaan konsep adalah $83,1 \%$ (sangat valid) dan persentase reliabilitas perangkat yaitu $82,0 \%$ (sangat tinggi).

Tahap terakhir dalam penelitian ini yaitu revisi produk final, berupa perbaikan atau pembenahan terhadap isi setiap produk berdasarkan data kualitatif yaitu berupa saran/masukan dari validator. Sehingga hasil 
akhirnya yaitu berupa produk perangkat pembelajaran yang layak dan siap digunakan dalam proses pembelajaran.

\section{SIMPULAN DAN SARAN}

Pengembangan pembelajaran model inkuiri terbimbing berbantuan media audiovisual ini telah berhasil dilakukan. Pembuktian tersebut yaitu dengan tingkat validitas 3,09 (valid) dan tingkat reliabilitas $82,3 \%$ (sangat tinggi). Sehingga produk perangkat pembelajaran telah siap digunakan dalam proses pembelajaran karena telah layak dan reliable berdasarkan hasil pengujian.

Produk perangkat pembelajaran yang tekah dikembangkan ini akan mampu menjadi solusi alternatif bagi guru dalam menunjang kegiatan proses belajar mengajar agar lebih efisien dan efektif dalam meningkatkan penguasaan konsep peserta didik. Selain itu juga produk ini dapat menjadi acuan untuk pengembangan produk perangkat pembelajaran dengan model atau variasi media pembelajaran yang lainnya. Serta dampaknya untuk peserta didik yaitu menarik perhatian belajar fisika serta tingginya konsep materi fisika yang dimiliki peserta didik.

Dibalik hasil dan ketercapaian produk perangkat pembelajaran yang berhasil dikembangkan, juga terdapat beberapa hal yang perlu diperhatikan lebih lanjut atau menjadi saran. Pengembangan perangkat harus tetap mengacu pada bentuk umumnya, bagi peneliti selanjutnya agar lebih tepat dan benar dalam penggunaan narasi pada video pembelajaran agar tidak terjadi miskonsepsi pada peserta didik.

\section{UCAPAN TERIMAKASIH}

Ucapan terimakasih kami sampaikan kepada pihak sekolah SMAN 1 Gerung sebagai tempat observasi, kemudian bapak dan ibu validator yang telah melakukan penilaian untuk pengujian kelayakan perangkat pembelajaran, serta semua pihak yang telah memberikan masukan dan saran untuk penyempurnaan artikel ini.

\section{DAFTAR RUJUKAN}

Annam, K. (2015). Pembelajaran Berbasis Inkuiri: Metode dan Aplikasi. Yogyakarta: Pustaka Pelajar.

Budiarso, A. S. (2017). Analisis Validitas Perangkat Pembelajaran Fisika Model Inkuiri Terbimbing untuk Meningkatkan Hasil Belajar Siswa SMA pada Materi Listrik Dinamis (The Analysis Validity of Physics Learning Device Guided Inquiry Model to
Improve Student Learning Outcomes S. Jurnal Edukasi, 4(2), 15-20.

Hade, L., \& Aswirna, P. (n.d.). Pengembangan Media Pembelajaran Fisika Menggunakan Corel Video Studio Pro X 7 Pada Materi Teori Kinetik Gas. Natural Science Jurnal. 5 (1). 740-753.

Hermanto, F., Soetjipto, S., \& Hidayat, M. T. (2016). Pengembangan Perangkat Pembelajaran IPA Model Inkuiri Terbimbing (Guided Inquiry) untuk Meningkatkan Pemahaman Konsep Siswa SMP. Jurnal Pengkajian IImu dan Pembelajaran Matematika dan IPA IKIP Mataram, 4(2): 55-70.

Kurniawati, I. D., \& Diantoro, M. (2014). Pengaruh Pembelajaran Inkuiri Terbimbing Integrasi Peer Instruction Terhadap Penguasaan Konsep Dan Kemampuan Berpikir Kritis Siswa. Jurnal Pendidikan Fisika Indonesia, 10(1), 36-46. https://doi.org/10.15294/jpfi.v10i1.30 49

Mulyasa, M. (2013). Pengembangan dan Implementasi Kurikulum. Bandung: PT Remaja Rosda Karya.

Prayudi, L. M. E., Sahidu, H., \& Gunawan, G. (2017). Pengaruh Penggunaan Media Audiovisual Dengan Pendekatan Metakognitif Berbasis Masalah Terhadap Hasil Belajar Fisika Siswa Kelas XI IPA di SMAN 1 Gerung Tahun Pelajaran 2016/2017. Jurnal Pendidikan Fisika dan Teknologi, 3(1), 55. https://doi.org/10.29303/jpft.v3i1.324

Purwanto, A. (2019). Pengembangan Perangkat Pembelajaran IPS Berorientasi Model Problem Based Learning Berbantuan Media Video Untuk Meningkatkan Hasil Belajar Siswa Kelas IV SD. Jurnal Review Pendidikan Dasar: Jurnal Kajian Pendidikan dan Hasil Penelitian, 5(1), 882.

https://doi.org/10.26740/jrpd.v5n1.p8 82-891

Sirait, R. (2012). Pengaruh Model Pembelajaran Inquiry Training Terhadap Hasil Belajar Siswa Pada Materi Pokok Usaha Dan Energi Kelas VIII MTs N-3 Medan. Jurnal Pendidikan Fisika,1(1), 27-32. https://doi.org/10.22611/jpf.v1i1.3377 Sudiarman., Soegimin, W,W., \& Susantini, E. (2015). Pengembangan Perangkat Pembelajaran Fisika Berbasis Inkuri 
Terbimbing Untuk Melatihkan

Keterampilan Proses Sains Dan

Meningkatkan Hasil Belajar Pada

Topik Suhu dan Perubahannya.

Pendidikan Sains Pascasarjana

Universitas Negeri Surabaya. 4(2), 658-671.

Sugiyono. (2014). Metode Penelitian

Pendidika: Pendekatan Kuantitatif, Kualitatif, Dan R\&D.

Bandung:Alfabeta.

Sumarauw, J. M., Ibrahim, M., \& Prastowo, T. (2017). Pengembangan Perangkat Pembelajaran Berbasis Inkuiri Terbimbing Berbantuan Simulasi Phet Dalam Pembelajaran IPA. Jurnal Penelitian PendidikanA \& A (Semarang), 34(1), 25-36. https://doi.org/10.15294/jpp.v34i1.10 909

Trianto, T. (2010). Mendesain Model Pembelajaran Inovatif-Progresif. Jakarta: Kencana Prenada Media Group.

Wahyuni, S., Kosim., \& Gunawan. (2018). Pengembangan Perangkat Pembelajaran Fisika Berbasis Inkuiri Terbimbing Berbantuan Eksperimen Untuk Meningkatkan Penguasaan Konsep Siswa. Jurnal Pendidikan Fisika dan Teknologi. 4(2). 240-246

Yeritia, S., Wahyudi., \& Rahayu, S. (2018). Pengaruh Model Pembelajaran Inkuiri Terbimbing Terhadap Penguasaan Konsep Dan Kemampuan Berpikir Kritis Fisika Peserta Didik Kelas $X$ SMAN 1 Kuripan Tahun Ajaran 2017/2018. Jurnal Pendidikan Fisika dan Teknologi. 3(2), 181-187.

Yulianci, S., Gunawan., \& Doyan, A. (2017). Model Inkuiri Terbimbing Berbantuan Multimedia Interaktif Untuk Meningkatkan Penguasaan Konsep Fisika Peserta Didik.Jurnal Pendidikan Fisika dan Teknologi.3(2), 146154.https://doi.org/11.16294/jpfi.v10i 1.4509 